\title{
Diet quality scores associated with improved cardiometabolic measures among African American adolescents
}

\author{
Kirstie Ducharme-Smith ${ }^{1}$, Tammy M. Brady ${ }^{2}$, Diane Vizthum ${ }^{3}$, Laura E. Caulfield ${ }^{1}$, Noel T. Mueller ${ }^{4}$, Summer Rosenstock ${ }^{5}$ and \\ Vanessa Garcia-Larsen ${ }^{1 凶}$
}

(c) The Author(s), under exclusive licence to the International Pediatric Research Foundation, Inc 2021

BACKGROUND: The Reversing the Negative cardiovascular Effects on Weight (ReNEW) Clinic is a prospective cohort study in children and adolescents ( $\leq 21$ years) at the Johns Hopkins Children's Center.

METHODS: Cross-sectional analysis between diet quality using the Alternative Healthy Eating Index (AHEI-2010), pro-inflammatory potential using the Children's Dietary Inflammatory Index (C-DII), and cardiometabolic outcomes. AHEI-2010 and C-DII scores were assessed by median intake determined from the sample distribution and associated with cardiometabolic measures using linear regression models. Changes in measures were evaluated in a sub-sample of participants invited to attend follow-up visits due to the presence of hypertensive blood pressure $(n=33)$.

RESULTS: Participants $(n=90)$ reported an average energy intake of $1790 \mathrm{kcal} /$ day (SD \pm 734$),$ AHEl-2010 score of 55.04 (SD \pm 9.86 ) (range: 0 to 110$)$ and C-DIl score of $-0.12( \pm 0.86)$ (range -5 to 5$)$. Participants with higher quality/anti-inflammatory diets trended towards more favorable cardiometabolic measures at baseline. Among the sub-sample $(n=33)$, there was a significant reduction in total energy $(m=-302 \mathrm{kcal} /$ day; $p$-value $=0.03)$ but no change in AHEl-2010 ( $p$-value $=0.73)$ or C-DIl score $(p$-value $=0.85)$ over follow-up.

CONCLUSIONS: Despite stable diet quality scores, outpatient dietary and behavioral counseling may be an effective tool to reduce energy intake in youth with overweight/obesity and elevated blood pressure.

Pediatric Research (2022) 92:853-861; https://doi.org/10.1038/s41390-021-01893-w

\section{IMPACT:}

- Diet quality scores among obese, hypertensive, African American adolescents were low and reflect a pro-inflammatory diet.

- Reported intake was negligible for fruits, whole grains, nuts, and legumes, and well above the daily limit for sodium and saturated fat.

- Participants with high quality/anti-inflammatory diet quality scores trended toward improved cardiometabolic measures.

- Outpatient dietary counseling resulted in reduced total energy intake.

\section{INTRODUCTION}

Cardiovascular disease (CVD) is the leading cause of death in the United States (US) among adults. ${ }^{1}$ In children and adolescents, trends over the past twenty years show a steady increase in the prevalence of obesity, ${ }^{2}$ incidence of Type 2 Diabetes Mellitus $(D M)^{3}$ as well as the persistent prevalence of hypertension ${ }^{4}$ making CVD risk a major public health problem in youth. Results from the SEARCH for Diabetes in Youth Study suggest that between 2002 and 2015, non-Hispanic (NH-) black youth have an increased risk of Type $2 \mathrm{DM}$, with the incidence rising by $6 \%$ per year. ${ }^{3}$ Moreover, in 2015-2016 NH-black adolescents were $60 \%$ more likely to have obesity ${ }^{2}$ and twice as likely to have hypertension ${ }^{4}$ than $\mathrm{NH}$-white youth.
Epidemiological evidence has consistently highlighted diet as a modifiable risk factor to prevent the development of cardiometabolic conditions in healthy US adolescents from the general population. ${ }^{5-8}$ Fruit and vegetable intake in this group has been inversely associated with abdominal obesity and metabolic syndrome. ${ }^{7,8}$ In addition to select components, overall diet quality has been associated with cardiometabolic conditions. Youth with higher adherence scores to the Healthy Eating Index (HEI) have lower serum cholesterol and improved glucose tolerance. ${ }^{9}$ Adolescents who consume a more pro-inflammatory diet, as measured by the dietary inflammatory index (DII), have higher waist circumference measures than those consuming more antiinflammatory diets. ${ }^{10}$

\footnotetext{
${ }^{1}$ Program in Human Nutrition, Department of International Health, Johns Hopkins Bloomberg School of Public Health, Baltimore, MD, USA. ${ }^{2}$ Pediatric Hypertension Program, The Johns Hopkins University School of Medicine, Baltimore, MD, USA. ${ }^{3}$ The Institute for Clinical and Translational Research, The Johns Hopkins Hospital, Baltimore, MD, USA. ${ }^{4}$ Program in Cardiovascular and Clinical Epidemiology, Department of Epidemiology, The Johns Hopkins Bloomberg School of Public Health, Baltimore, MD, USA. ${ }^{5}$ Social and Behavioral Interventions, Department of International Health, The Johns Hopkins Bloomberg School of Public Health, Baltimore, MD, USA. ${ }^{\top}$ email: vgla@jhu.edu
} 


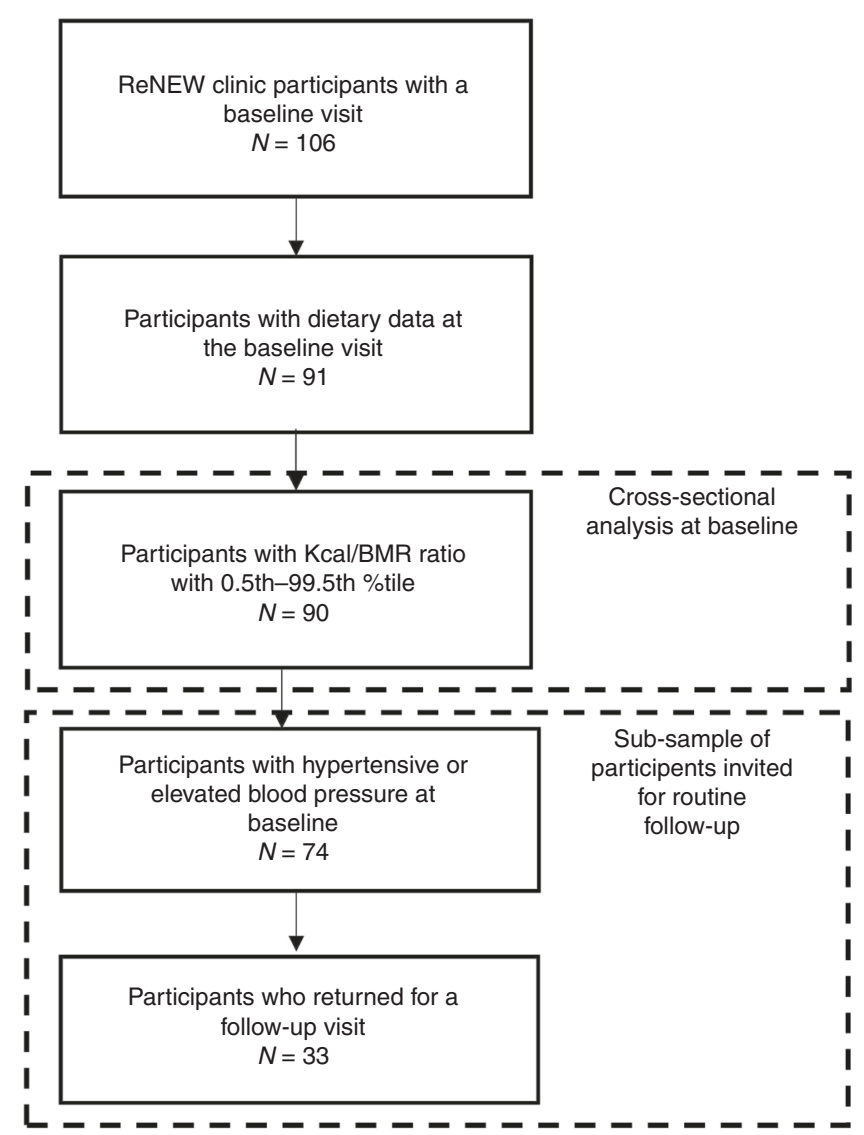

Fig. 1 Flow diagram of ReNEW clinic participants included in the study. Among participants enrolled in the ReNEW clinic cohort study ( $N=106$; Fig. 1$)$, only those with dietary data were considered for the cross-sectional analysis $(N=91)$. Of the sub-group of participants with dietary data who were invited to receive routine follow-up care $(n=74), 33$ attended follow-up visits within 12months of baseline.

There are a limited number of studies that have examined the association of diet quality with cardiometabolic health in groups at high risk for the development of CVD. In addition, there is a need to establish and promote clinical interventions that are effective at improving diet intake and diet quality. The ReNEW Clinic is an interdisciplinary clinic in Baltimore, MD focused on the evaluation and treatment of obesity and hypertension in children and adolescents ( $\leq 22$ years of age). Youth receiving treatment in this clinic are invited to participate in the ReNEW Clinic Cohort study, a prospective, longitudinal observational study of consecutive patients from the clinic. The majority of cohort participants are African American adolescents at high risk for the development of cardiovascular disease, which is an understudied group. The purpose of the present study is to 1 . Investigate the cross-sectional association between diet quality and anthropometric/cardiometabolic traits among ReNEW Clinic Cohort study participants at baseline and, 2. Evaluate changes in dietary and cardiometabolic measures in a sub-sample of participants who were invited to attend follow-up visits due to the presence of hypertensive blood pressure.

\section{METHODS}

The ReNEW Clinic Cohort Study (NCT03816462) is human subjects research that has been approved by the Johns Hopkins IRB (IRB00056175). ${ }^{11}$ Enrollment began in January 2015 and is ongoing through September 2025 with the goal to recruit 200 participants. This is a preliminary cross-sectional analysis of participants who were recruited between January 2015 through December 2020.

\section{Study sample}

Participants between birth and 22 years of age with overweight or obesity who are referred to the clinic for evaluation of elevated blood pressure are eligible. At their clinic visit, interested participants and their guardians are invited to join the ReNEW Clinic Cohort Study, an observational research cohort study. Participants in the cohort study agree to have their clinical data abstracted from the electronic medical record (EMR) and entered into a longitudinal clinic registry. The study is discussed with participants in the presence of their parent or legal guardian and those who agree to participant sign consent ( $\geq 18$ years) or assent $(<18$ years) as appropriate. Cohort participants who present with an elevated or hypertensive blood pressure at their initial visit are invited to attend follow-up visits to receive routine care every 3-6 months ( $n=88 / 106 ; 90 \%$ of the original cohort), whereas those who are found to have a normal blood pressure at their initial visit are invited for an additional follow-up visit at 6 months for additional weight management and to screen for the development of elevated or hypertensive BP if desired.

At clinic visits, standardized information is collected on blood pressure, anthropometrics, diet history, and other clinical data measurements. Among participants enrolled in the ReNEW clinic cohort study $(N=106$; Fig. 1), only those with dietary data were considered for the cross-sectional analysis $(N=91)$. Of the sub-group of participants with dietary data who were invited to receive routine follow-up care $(n=74), 33$ attended followup visits within 12-months of baseline ( $m=1.5 \pm 0.8$ visits). For the purpose of this study, follow-up was identified as the furthest visit with dietary data ( $m=7.2 \pm 3.2$ months of baseline).

During ReNEW clinic visits, youth meet with and receive treatment from the clinical team. Patients and families receive interdisciplinary pediatric care and meet with a pediatric nephrologist, research dietitian, a behavioral psychologist, and a physical therapist at each clinic visit. Children and their families receive nutrition education on a variety of topics including increasing fruits/vegetables, limiting sodium intake, promoting sugar-free beverages, healthy alternative snacks, promoting three meals per day, and portion control individualized to the participant and then reiterated with the behavioral psychologist. Youth in this clinic are incentivized with prizes for healthy lifestyle choices and prior to the beginning of COVID-19 were offered a healthy snack to try at each visit (cross-sectional: $n=87 / 90$; sub-sample: baseline- $n=71 / 74$ Follow-up- $n=$ 33/33). Barriers to weight management are addressed and free-standing scales, as well as 3-6 months YMCA memberships, were offered to youth between 2015-2019.

\section{Baseline characteristics}

Demographic characteristics of participants are collected at baseline visits. Participant's age was abstracted from the EMR via the filed date of birth. Sex was obtained from participant self-report or via EMR filed sex (male, female). Race/ethnicity was obtained from forms detailing participants selfdescribed race at the baseline clinic visit. Average household income is a continuous variable determined from U.S. census estimates of zip-code level data based on participant/parent-reported home address.

Documented medical history including presence of overweight/obesity, obstructive sleep apnea, high cholesterol, pre-diabetes and diabetes (type 2) was obtained from the participants EMR confirmed by physician diagnosis. Birth information (history of prematurity and birth weight) was collected via self-report from baseline data collection forms. Birth weight data was used to classify participants as low birth weight $(<2.5 \mathrm{~kg})$, normal birth weight $(2.5-<4.0 \mathrm{~kg})$ or high birth weight $(\geq 4.0 \mathrm{~kg})$. Self-reported family history including obesity, hypertension, heart attack, high cholesterol, diabetes (type 1 or type 2), and kidney disease was collected on health history forms at baseline visits.

\section{Dietary intake assessment and diet quality exposures}

Dietary measures are collected at baseline and follow-up via self-report either through 3-days diet records that are completed prior to the clinic and then reviewed by the research dietitian with the participant and their family or by the guided 24-h recall at the clinic visit (3-day diet record: $n=$ $27 / 90$ or $30 \%, 24-$ h recalls: $n=63 / 90$ or $70 \%$ ). Both instruments relied on free form reporting of food items and portion sizes that was then confirmed with the dietitian utilizing standard measures (i.e., cups, tablespoons) with visual aids to assist accurate reporting. Brand names 
or similar items were collected whenever possible and probing questions were utilized to identify commonly forgotten items. Individual foods and amounts reported for each day of the 3-days diet record or for single day 24-h recall were uploaded into the Nutrition Data System for Research (NDSR) software (versions 2014-2019). ${ }^{12,13}$ NDSR data files 04 (nutrient data at the daily totals) and 09 (food group serving counts at the daily totals) were exported from NDSR into Stata where information was linked to the clinic visit the data was collected at as either a single 24-h recall or an average of the 3-days diet record.

Diet quality was determined using the Alternative Healthy Eating Index (AHEI-2010) and the Children's Dietary Inflammatory Index (C-DII) following the specific criteria for each index. ${ }^{14,15}$ The AHEI-2010 index was selected based on the inclusion of select dietary components that have been positively or negatively associated with cardiometabolic health including fruits/vegetables, ${ }^{16}$ nuts/legumes, ${ }^{17}$ unsaturated fatty acids, red/processed meat, ${ }^{18}$ sugar-sweetened beverages (SSB) ${ }^{19}$ and sodium. ${ }^{20}$ The C-DII was additionally selected as a dietary measure because anti-inflammatory diets have been associated with improvements in lipid profile ${ }^{10}$ and decreased likelihood of overweight/obesity in adolescents. ${ }^{21}$ Potassium is not included in either index but was described in this study as higher intakes have been inversely associated with blood pressure in adolescents. ${ }^{22,23}$

AHEI. The Alternative Healthy Eating Index (AHEI-2010) score is based on 11 components of dietary intake scored from 0 to 10 (worst to best) with the total score ranging between 0 and 110 (higher = better diet quality). ${ }^{14}$ The calculation of the AHEI-2010 score within this sample was based on reported consumption of fruit (servings per day), vegetables (servings per day), whole grains (g/d), nuts and legumes (servings per day), omega-3 fatty acid (mg/d), polyunsaturated fatty acid (PUFA; \%kcal), trans fat (\% $\mathrm{kcal}$ ) red/processed meat (servings per day), SSB (servings per day), sodium $(\mathrm{mg} / \mathrm{d})$ and alcohol (drinks/d). Scoring criteria for individual food component was taken from the original paper by Chiuve et al. ${ }^{14}$ except for alcohol which was scored between 0 and 2.5; with non-drinkers $(n=88$; $98 \%$ of the sample) receiving a score of 2.5 and moderate drinkers $(n=2 ;$ $2 \%$ of the sample) receiving a score of 0 .

C-DII. The C-DIl score is a calculated parameter based on 25 components of dietary intake with total scores roughly ranging between -5 and 5 (lower = better diet quality). ${ }^{15}$ The calculation of the C-DII score within this sample was based on 25 nutrients and food components including total energy $(\mathrm{kcal} /$ day), protein $(\mathrm{g} /$ day), carbohydrate $(\mathrm{g} /$ day), total fat $(\mathrm{g} /$ day), saturated fat (g/day), mono-unsaturated fatty acid (MUFA) (g/day), PUFA (g/day), cholesterol (mg/day), dietary fiber ( $/$ /day), Vitamin A (RE/day), Vitamin D (mcg/day), Vitamin E (AT EQ/day), Vitamin C (mg/day), betacarotene $(\mathrm{mcg} /$ day), thiamin $(\mathrm{mg} /$ day), riboflavin $(\mathrm{mg} /$ day), niacin $(\mathrm{mg} /$ day), folate $\left(\mathrm{mg} /\right.$ day), Vitamin $B_{6}\left(\mathrm{mg} /\right.$ day), Vitamin $B_{12}(\mathrm{mcg} /$ day), magnesium ( $\mathrm{mg} /$ day), iron $(\mathrm{mg} /$ day), selenium $(\mathrm{mcg} /$ day), zinc $(\mathrm{mg} /$ day) and alcohol (grams/day). To derive the individual C-DIl scores, the global average intake was subtracted from the reported daily intake of each nutrient and divided by the standard deviation of the global daily intake, obtaining a $z$-score which was converted into a centered percentile score. ${ }^{24}$ This score was then multiplied with an overall inflammatory effect score. All 25 nutrient-specific effect scores were then summed to obtain the total C-DIl score. ${ }^{15}$

\section{Cardiometabolic characteristics}

Anthropometric measures including height $(\mathrm{cm})$, weight $(\mathrm{kg})$, and waist circumference $(\mathrm{cm})$ are collected at baseline and follow-up as a part of the clinical care process. Height is measured once to the nearest $0.1 \mathrm{~cm}$ using a wall-mounted stadiometer. Weight is measured once to the nearest $0.1 \mathrm{~kg}$ using a digital scale. Height and weight measurements were used to calculate age and sex standardized body mass index (BMI) $z$-scores (BMIz) using the CDC 2000 growth reference population in participants $\leq 18$ years with weight status classified as "Underweight" $<5$ th \%tile, "Normal" 5 th $-<$ 85 th \%tile, "Overweight" 85 th $-<95$ th \%tile or "Obese" $\geq 95$ th \%tile. ${ }^{25}$ BMI was calculated as weight (kilograms) over squared height (meters ${ }^{2}$ ) in participants 19-21 years with weight status classified as "Underweight" $<18.5 \mathrm{~kg} / \mathrm{m}^{2}$, "Normal" $18.5-24.9 \mathrm{~kg} / \mathrm{m}^{2}$, "Overweight" $25-29.9 \mathrm{~kg} / \mathrm{m}^{2}$, or Obese $\geq 30 \mathrm{~kg} / \mathrm{m}^{2}$.

Waist circumference. Waist circumference (WC) was measured by the trained research dietitian using Rosscraft anthropometric tape around the participant's umbilicus at the end of normal expiration. ${ }^{27}$ WC was measured to the nearest $0.1 \mathrm{~cm}$. Waist circumference measurements were used to calculate age and sex standardized WC $z$-scores (z-WC) based on NHANES III data. ${ }^{28}$

Blood pressure. Blood pressure was measured at each clinic visit by the same individual (TMB) via manual auscultation after $5 \mathrm{~min}$ of rest in the right upper arm with a calibrated aneroid sphygmomanometer. Cuff size was determined via mid-upper arm circumference measurement. Children were seated with legs uncrossed, feet on the ground, back supported and arm supported during the measurements. ${ }^{29}$ Three measurements were taken 30 $s$ apart and averaged together for one composite measurement at each clinic visit for systolic and diastolic blood pressure (SBP, DBP). Blood pressure index was calculated as raw, mean blood pressure divided by the age, sex, and height specific blood pressure at the 95th percentile (\%tile) for all participants (95\%tile measures at 17 years of age were used for those $>17$ years); blood pressure index $\geq 1$ can be interpreted as an abnormal blood pressure across all age/sex/height categories. Hypertensive BP was identified based on the American Academy of Pediatrics (AAP) 2017 Clinical Practice Guidelines ( 12 years, SBP or DBP $\geq 95$ th \%tile; $\geq 13$ years, SBP or $\mathrm{DBP} \geq 130 / 80 \mathrm{mmHg})^{29}$

Left ventricular mass index. Left ventricular mass index (LVMI) was determined in participants who received an echocardiogram as left ventricular mass in grams/(height in $\mathrm{cm})^{2.7}$. LVMl $_{\text {index }}$ was calculated as LVMI divided by the age/sex standardized LVMI measures at the 95th \%tile; $\mathrm{LVMI}_{\text {index }}>1$ was classified as left ventricular hypertrophy. ${ }^{30}$

Plasma Glucose and Hemoglobin A1c. Plasma glucose was measured in $\mathrm{mg} / \mathrm{dL}$ from participant serum samples. Fasting status was not identified, therefore impaired fasting glucose status could not be determined. Hemoglobin A1c ( $\mathrm{HbA1c}$ ) was measured in those suspected of being at risk for diabetes. Pre-diabetes and diabetes thresholds were based on American Diabetes Association criteria (pre-diabetes: $\mathrm{HbA} 1 \mathrm{c} \geq 5.7 \%$ \& $\mathrm{HbA} 1 \mathrm{c} \leq 6.4 \%$; Diabetes: $\mathrm{HbA} 1 \mathrm{c} \geq 6.5 \%)^{31}$

Lipid markers. Lipid profile (total cholesterol, serum HDL-cholesterol, triglycerides) were measured in $\mathrm{mg} / \mathrm{dL}$ from participant serum samples. Non-HDL cholesterol was determined by subtracting HDL-cholesterol from total cholesterol. Low HDL-cholesterol was identified based on National Heart Lung and Blood Institute (NHLBI) guidelines ( $\mathrm{HDL}<40 \mathrm{mg} / \mathrm{dL}$ ). ${ }^{32}$

Medications. Participants self-reported use of prescribed medications at baseline visits that was then confirmed via the EMR. Additionally, participants could be prescribed medications at clinic visits based on clinical status and physician diagnosis. Participants were considered to be taking blood pressure medication if they reported use or were prescribed angiotensin-converting enzyme inhibitors, angiotensin II receptor blockers, beta blockers, alpha blockers, alpha-beta blockers, calcium channel blockers, centrally acting alpha-2 agonist, direct vasodilators, diuretic-loop, diuretic-potassium sparing, diuretic-thiazide and combination antihypertensive medications. Diabetes medication use was confirmed if participants were taking or prescribed insulin and/or oral hypoglycemic agents.

\section{Data analyses}

Categorical variables were presented as numbers with percentages. Continuous variables were visualized to determine the distribution of sample characteristics and presented as means with standard deviation. Non-normally distributed data were presented as medians with interquartile range. Participants with unrealistic reporting of energy intake were excluded from the analysis determined as kilocalorie/basal metabolic rate ratio (Kcal/BMR) ratio $<0.5$ th percentile or $>99.5$ th percentile. ${ }^{33}$ Baseline characteristics are presented from the ReNEW Clinic Cohort overall $(n=$ 106) and among the final sample with realistic dietary data $(n=90)$. Differences in baseline characteristics between samples were explored by independent $t$-tests for continuous variables and by chi-square tests for categorical characteristics. Average and median dietary intake was compared with recommended guidelines and thresholds utilizing the Dietary Guidelines for Americans (DGA), ${ }^{34}$ the scoring criteria from Chiuve et al. ${ }^{14}$ and the Dietary Reference Intakes (DRI) specific to each nutrient. $^{35-37}$

Cross-sectional associations between diet quality (comparing higher quality/anti-inflammatory vs. lower quality/pro-inflammatory diets determined via median split AHEl-2010 and C-DIl scores based on the sample distribution) and cardiometabolic characteristics [SBP Index, DBP Index, SBP $(\mathrm{mmHg}), \mathrm{DBP}(\mathrm{mmHg}), \mathrm{LVMI}\left(\mathrm{g} / \mathrm{m}^{2.7}\right), \mathrm{BMl}, \mathrm{z}-\mathrm{WC}, \mathrm{HbA} 1 \mathrm{c}(\%)$ and non- 
HDL cholesterol $(\mathrm{mg} / \mathrm{dL})]$ were evaluated using linear regression models. All models controlled for age (years), sex (boys, girls), daily energy intake (scaled per $1000 \mathrm{kcal}$ ), and average neighborhood household income (annual in US dollars). Models for SBP Index, DBP Index, SBP, DBP, and LVMI also controlled for blood pressure medication (yes, no); model for HbA1c additionally controlled for diabetes medication (yes, no). Additional covariates explored that did not significantly impact the association were race/ethnicity (non-Hispanic White, non-Hispanic Black, Hispanic, other), low birth weight (yes, no; defined as birth weight $<2.5 \mathrm{~kg}$ ), and family history (overweight/obesity, hypertension, diabetes).

Differences in general characteristics of those who were invited to attend follow-up visits $(n=74)$ who attended $(n=33)$ or did not attend ( $n$ $=41$ ) follow-up visits were explored and presented in supplemental tables. Differences in cardiometabolic characteristics and dietary intake over follow-up among the sub-sample who attended follow-up visits $(n=33)$ were evaluated using longitudinal linear or logistic mixed-effects models with robust variance. Differences in total energy intake by type of dietary education received were explored and presented in a Supplemental Figure. Significance was set at $p$-value $<0.05$. Stata 14 was used for all analyses. $^{38-40}$

\section{RESULTS}

Of the 106 participants enrolled in the ReNEW clinic cohort (Fig. 1), 91 provided dietary data at their baseline visit (86\% of baseline sample). One participant was excluded for unrealistic intake (defined as $\mathrm{kcal} / \mathrm{BMR}$ ratio $<0.5$ th or $>99.5$ th \%tile) thus the final sample was comprised of 90 at baseline. Participants in the final sample $(N=90$; Table 1$)$ were on average 13.4 years $(S D \pm 3.9$ years; age range $4-21$ years), majority male $(n=51 ; 57 \%)$ and most identified as non-Hispanic Black $(n=73 ; 81 \%)$. Based on zipcode level census data of participants, the median neighborhood household income was $54 \mathrm{~K} /$ year (IQR: $40-69 \mathrm{~K}$ ), and around $10 \%$ of households in the area fall below the poverty line. Based on documented medical history, the majority of the sample $(n=79$; $88 \%$ ) had a history of overweight/obesity and around 1 in 3 were medically diagnosed with obstructive sleep apnea $(n=25 ; 28 \%)$ or pre-diabetes/type 2 diabetes $(n=25 ; 28 \%)$. The average birth weight was $3.09( \pm 0.82 \mathrm{~kg})$ and around 1 in 4 participants $(n=19$; $23 \%)$ were classified as having low-birth weight $(<2.5 \mathrm{~kg})$. Family history of co-morbidities was high overall and highest for hypertension $(n=75 ; 83 \%)$ and diabetes type 1 or type $2(n=$ 59; 66\%). There were no significant differences in demographic characteristics between the final sample with dietary data included in the cross-sectional analysis and the total ReNEW clinic.

Based on BMIz ( $\leq 18$ years; $n=81$ ) and BMI ( $>18$ years; $n=9)$ all of the participants were classified as overweight $(n=6 ; 7 \%)$ or obese $(n=84 ; 93 \%)$ at baseline (Table 2$)$ and average waist circumference $z$-score was 2.66 (SD \pm 0.69 ). Based on blood pressure percentiles ( $\leq 12$ years; $n=40$ ) and raw blood pressure measures ( $\geq 13$ years; $n=50$ ), $48 \%$ of participants had blood pressure in the hypertensive range. ${ }^{29}$ Of participants with LVMI measures $(n=82), 72 \%$ of children had left ventricular hypertrophy. ${ }^{30}$ Average HbA1c was $6.1 \%(S D \pm 1.5)$, with $26 \%(n=19)$ of participants having an $\mathrm{HbA} 1 \mathrm{c}$ in the pre-diabetic range and $13 \%$ $(n=9)$ with $\mathrm{HbA} 1 \mathrm{c}$ in diabetic range. The average HDL-cholesterol was $45.2 \mathrm{mg} / \mathrm{dL}$ (SD \pm 10.3 ), and $32 \%$ of participants had low HDLcholesterol based on NHLBI thresholds. ${ }^{32}$ The average non-HDL cholesterol was $115.4 \mathrm{mg} / \mathrm{dL}$ (SD \pm 33.9 ), and $16 \%$ of participants had elevated non-HDL cholesterol. Almost $40 \%$ of participants were on blood pressure medications $(n=35)$, and $13 \%$ were on diabetes medications $(n=12)$ at baseline.

The majority of the dietary data (70\%) were collected as $24-\mathrm{h}$ recalls at the clinic visit and the remaining (30\%) were collected as 3-days food records. At baseline, the average AHEI score of participants was 55.04 (SD \pm 9.86$)$, and the average C-DIl score of participants was $-0.12(\mathrm{SD} \pm 0.86)$ (Table 3 ). Participants reported consuming an average of $1790 \mathrm{kcal} /$ day $(S D \pm 734)$, and intake increased with higher age categories. Percent of energy from fat,
Table 1. Baseline characteristics of the overall ReNEW clinic cohort $(N=106)$ and participants included in the final sample $(n=90)$.

\begin{tabular}{|c|c|c|c|}
\hline & $\begin{array}{l}\text { ReNEW } \\
\text { clinic cohort }\end{array}$ & $\begin{array}{l}\text { Final sample } \\
\text { for analysis }\end{array}$ & $p$-value ${ }^{a}$ \\
\hline Sample size & $N=106$ & $N=90$ & \\
\hline Age, mean $\pm S D$ & $13.4 \pm 3.9$ & $13.4 \pm 3.9$ & 0.75 \\
\hline Male sex, $n(\%)$ & $64(60.4)$ & $51(56.7)$ & 0.06 \\
\hline \multicolumn{4}{|l|}{ Race/ethnicity, $n$ (\%) } \\
\hline Non-Hispanic Black & $82(77.4)$ & $73(81.1)$ & 0.05 \\
\hline Non-Hispanic White & $14(13.2)$ & $8(8.9)$ & \\
\hline Hispanic & $6(5.7)$ & $5(5.6)$ & \\
\hline Other $^{\mathrm{b}}$ & $4(3.8)$ & $4(4.4)$ & \\
\hline \multicolumn{4}{|c|}{ SES Census Information, median (IQR) ${ }^{\mathrm{C}}$} \\
\hline $\begin{array}{l}\text { Less than high school } \\
\text { education, \% }\end{array}$ & $\begin{array}{l}16.1 \\
(9.4-21.7)\end{array}$ & $\begin{array}{l}16.1 \\
(10.4-21.7)\end{array}$ & 0.81 \\
\hline Population unemployed, \% & $\begin{array}{l}7.7 \\
(4.8-13.7)\end{array}$ & $7.9(4.8-14.1)$ & 0.35 \\
\hline $\begin{array}{l}\text { Average household income } \\
\text { (annual in US dollars) }\end{array}$ & $\begin{array}{l}55.5 \mathrm{~K} \\
(39.4-72.5 \mathrm{~K})\end{array}$ & $\begin{array}{l}54.2 \\
(39.6-68.8 \mathrm{~K})\end{array}$ & 0.12 \\
\hline $\begin{array}{l}\text { Households receiving } \\
\text { public assistance, \% }\end{array}$ & $\begin{array}{l}4.7 \\
(2.1-10.1)\end{array}$ & $4.8(2.3-10.3)$ & 0.84 \\
\hline Below than poverty line, $\%$ & $\begin{array}{l}9.4 \\
(4.2-19.6)\end{array}$ & $9.9(4.6-22.7)$ & 0.11 \\
\hline \multicolumn{4}{|c|}{ Documented medical history, $n(\%)$} \\
\hline Overweight/obesity & $94(88.7)$ & $79(87.8)$ & 0.49 \\
\hline Obstructive sleep apnea & $31(29.3)$ & $25(27.8)$ & 0.43 \\
\hline High cholesterol & $9(8.5)$ & $7(7.8)$ & 0.53 \\
\hline Pre-diabetes (Type 2) & $18(17.0)$ & $13(14.4)$ & 0.10 \\
\hline Diabetes (Type 2) & $15(14.2)$ & $12(13.3)$ & 0.57 \\
\hline \multicolumn{4}{|l|}{ Early life/gestational factors } \\
\hline Prematurity, $n(\%)^{d}$ & $16(15.1)$ & $14(15.6)$ & 0.75 \\
\hline Birth weight ${ }^{d}$, mean $\pm S D$ & $3.05 \pm 0.84$ & $3.09 \pm 0.82$ & 0.28 \\
\hline \multicolumn{4}{|l|}{ Birth weight classification, $n$ (\%) } \\
\hline Low birth weight & $24(24.5)$ & $19(23.2)$ & 0.78 \\
\hline Normal birth weight & $66(67.4)$ & $56(68.3)$ & \\
\hline High birth weight & $8(8.2)$ & $7(8.5)$ & \\
\hline \multicolumn{4}{|l|}{ Reported family history, $n(\%)^{\mathrm{e}}$} \\
\hline Obesity & $15(14.2)$ & $13(14.4)$ & 0.84 \\
\hline Hypertension & $88(83.0)$ & $75(83.3)$ & 0.84 \\
\hline Heart attack & $31(29.3)$ & $24(26.7)$ & 0.17 \\
\hline High cholesterol & $33(31.1)$ & $26(28.9)$ & 0.24 \\
\hline Diabetes (Type 1 or Type 2) & $69(65.1)$ & $59(65.6)$ & 0.81 \\
\hline Kidney disease & $21(19.8)$ & $18(20.0)$ & 0.91 \\
\hline
\end{tabular}

${ }^{a}$ Independent $t$-tests or chi-square tests performed between participant characteristics and sample groups (ReNEW Clinic Cohort and Final Sample). ${ }^{b}$ Other race/ethnicity includes Asian, multi-racial, and unspecified.

'Socioeconomic status (SES) information based on patient census tract information.

${ }^{\mathrm{d}}$ History of prematurity is self-reported on all participants at baseline. Birth weight data obtained in 98 subjects (missing $n=8$ ) and used to classify participants as low birth weight $(<2.5 \mathrm{~kg})$, normal birth weight $(2.5-<4.0 \mathrm{~kg})$ or high birth weight $(\geq 4.0 \mathrm{~kg})$.

e Family history (mother/father, siblings, grandparents) is self-reported from parents at baseline.

protein, and carbohydrate were $33.3 \%, 17.3 \%$, and $49.3 \%$, respectively. Compared with recommendations, median intake was negligible for fruit and nuts/legumes ( 0.00 servings/day) and low for vegetables (1.63 servings/day) and whole grains $(4.7 \mathrm{~g} /$ day). Median intake of dietary fat, vitamins, and minerals are also presented in Table 3. Notably, median intake was high for saturated fat ( $11 \%$ of total energy) and sodium (3191 mg/day) but 
Table 2. Cardiometabolic measures of participants included in the final sample $(N=90)$

\begin{tabular}{|c|c|}
\hline & Final sample \\
\hline Sample size & $N=90$ \\
\hline \multicolumn{2}{|l|}{ Anthropometrics, mean $\pm S D$} \\
\hline BMIz ( $\leq 18$ years) $n=81$ & $2.56 \pm 0.38$ \\
\hline BMl, $\mathrm{kg} / \mathrm{m}^{2}$ (>18 years) $n=9$ & $47.6 \pm 12.1$ \\
\hline \multicolumn{2}{|l|}{ Cardiometabolic measures, mean $\pm S D$} \\
\hline$W C(\mathrm{~cm})^{\mathrm{a}}$ & $112.2 \pm 21.7$ \\
\hline$z-W C^{a}$ & $2.66 \pm 0.69$ \\
\hline \multicolumn{2}{|l|}{$\mathrm{BP}, \mathrm{mmHg}$} \\
\hline $\mathrm{SBP}, \mathrm{mmHg}$ & $124.0 \pm 15.2$ \\
\hline $\mathrm{DBP}, \mathrm{mmHg}$ & $66.3 \pm 10.9$ \\
\hline \multicolumn{2}{|l|}{ BP index ${ }^{b}$} \\
\hline SBP index & $0.98 \pm 0.06$ \\
\hline DBP index & $0.75 \pm 0.11$ \\
\hline Left ventricular mass index, $\mathrm{g} / \mathrm{m}^{2.7}$ (LVMI) $^{\mathrm{c}}$ & $49.7 \pm 13.6$ \\
\hline LVMI index ${ }^{d}$ & $1.35 \pm 0.33$ \\
\hline Glucose, mg/dL ${ }^{e}$ & $100.3 \pm 47.6$ \\
\hline Hemoglobin A1c, $\%^{f}$ & $6.1 \pm 1.5$ \\
\hline Total cholesterol, $\mathrm{mg} / \mathrm{dL}^{\mathrm{g}}$ & $160.6 \pm 32.1$ \\
\hline HDL-cholesterol, mg/dL ${ }^{\mathrm{g}}$ & $45.2 \pm 10.3$ \\
\hline Non-HDL cholesterol, mg/dL ${ }^{\mathrm{g}}$ & $115.4 \pm 33.9$ \\
\hline Serum triglycerides, mg/dL ${ }^{g}$ & $111.5 \pm 66.9$ \\
\hline \multicolumn{2}{|c|}{ Cardiometabolic Classification based on objective clinical measures, $n /$ total (\%) } \\
\hline Overweight/obese $^{\mathrm{h}}$ & $90 / 90(100.0)$ \\
\hline Hypertensive $\mathrm{BP}^{\mathrm{i}}$ & $43 / 90(47.8)$ \\
\hline Left ventricular hypertrophy ${ }^{d}$ & $59 / 82(72.0)$ \\
\hline Pre-diabetes ${ }^{f}$ & 19/72 (26.4) \\
\hline Diabetes ${ }^{f}$ & 9/72 (12.5) \\
\hline Low HDL-cholesterol ${ }^{\mathrm{g}}$ & 23/73 (31.5) \\
\hline Elevated non-HDL cholesterol ${ }^{g}$ & 12/73 (16.4) \\
\hline \multicolumn{2}{|l|}{ Medications, n/total (\%) } \\
\hline Blood pressure medication ${ }^{j}$ & $35 / 90(38.9)$ \\
\hline Diabetes medication ${ }^{\mathrm{k}}$ & 12/89 (13.3) \\
\hline
\end{tabular}

$B M I z$ body-mass index $z$-score, $B M I$ body mass index, WC waist circumference, $z$-WC waist circumference $z$-score, $B P$ blood pressure, $S B P$ systolic blood pressure, $D B P$ diastolic blood pressure, $L V M I$ left ventricular mass index, $H D L$ high-density lipoprotein cholesterol.

${ }^{a}$ Waist Circumference $(\mathrm{cm})(n=80)$. Waist circumference measurements were used to calculate age and sex standardized WC Z-scores using the NHANES III growth reference population. ${ }^{28}$

${ }^{\mathrm{b}}$ Blood pressure measured in all participants $(n=90)$. Blood pressure index was calculated as the mean of replicate blood pressure in $\mathrm{mmHg}$ divided by the age, sex, and height specific blood pressure at the 95th percentile (\%tile) for all participants (95\%tile measures at 17 years of age were used for those $>17$ years).

'Left ventricular mass index (LVMI) determined in patients who received an echocardiogram $(n=82)$.

${ }^{\mathrm{d}} \mathrm{LVMI}{ }_{\text {index }}$ was calculated as LVMI divided by the age/sex standardized LVMI measures at the 95th \%tile; LVMI index $>1$ was classified as left ventricular hypertrophy. ${ }^{30}$

ePlasma glucose $(n=76)$. Fasting status not determined.

${ }^{f}$ Hemoglobin A1c $(n=72)$. Pre-diabetes and diabetes thresholds based on ADA criteria (pre-diabetes: $H \mathrm{bA} 1 \mathrm{c} \geq 5.7 \%$ \& $\mathrm{HbA} 1 \mathrm{c} \leq 6.4 \%$; diabetes: $\mathrm{HbA} 1 \mathrm{c} \geq 6.5 \%)^{31}$

${ }^{9}$ Total cholesterol, serum HDL-cholesterol, and serum triglycerides $(n=73)$. Non-HDL cholesterol was determined by subtracting HDL-cholesterol from total cholesterol. Low-HDL based on NHLBI guidelines defined as $\mathrm{HDL}<40$ $\mathrm{mg} / \mathrm{dL}$. Elevated non-HD defined as non-HDL cholesterol $\geq 145 \mathrm{mg} / \mathrm{dL}^{32}$
${ }^{\mathrm{h}}$ Classification of weight status based on age and sex standardized Body Mass Index (BMI) $z$-scores (12-18 years) or BMI $\left(\mathrm{kg} / \mathrm{m}^{2}\right)(19-21$ years) and determined as follows: 12-18 years "Underweight" <5th \%tile, "Normal" 5th -85 th \%tile, "Overweight" 85th - 95th \%tile or "Obese" $\geq 95$ th \%tile; $19-21$ years "Underweight" < $18.5 \mathrm{~kg} / \mathrm{m}^{2}$, "Normal" $18.5-24.9 \mathrm{~kg} / \mathrm{m}^{2}$, "Overweight" $25-29.9 \mathrm{~kg} / \mathrm{m}^{2}$, or Obese $\geq 30 \mathrm{~kg} / \mathrm{m}^{2}$. ${ }^{26}$

iHypertensive BP was determined based on the American Academy of Pediatrics (AAP) 2017 Clinical Practice Guidelines ( $\leq 12$ years, SBP or DBP $\geq$ 95th \%tile; $\geq 13$ years, SBP or DBP $\geq 130 / 80 \mathrm{mmHg}$ ). ${ }^{29}$.

${ }^{\mathrm{j} A n t i h y p e r t e n s i v e ~ m e d i c a t i o n s ~ i n c l u d e d ~ a n g i o t e n s i n-c o n v e r t i n g ~ e n z y m e ~}$ inhibitors, angiotensin II receptor blockers, beta blockers, alpha blockers, alpha-beta blockers, calcium channel blockers, centrally acting alpha-2 agonist, direct vasodilators, diuretic-loop, diuretic-potassium sparing, diuretic-thiazide, and combination antihypertensive medications.

kDiabetes medications included insulin and oral hypoglycemic agents.

low for MUFA ( $11 \%$ of total energy), PUFA ( $8 \%$ of total energy), beta-carotene $(534 \mathrm{mcg} /$ day), Vitamin D $(3.8 \mathrm{mcg} /$ day $)$, Vitamin E (6.6 alpha-tocopherol equivalents/day), potassium ( $1828 \mathrm{mg} /$ day) and magnesium ( $205 \mathrm{mg} /$ day). Reported intake of remaining dietary components met recommendations for goal ranges (fat, protein, carbohydrate), daily goal intake (omega-3 fatty acid, Vitamin A, Vitamin C, Vitamin $B_{6}$, thiamin, riboflavin, niacin, total folate, zinc, selenium) as well as daily limits (red/processed meat, SSB, alcohol, cholesterol, trans fat, iron).

Associations between diet quality, pro-inflammatory diet, and cardiometabolic measures at baseline can be found in Tables 4 and 5 . There were no significant associations between diet quality scores and cardiometabolic components. However, there were non-significant trends toward lower cardiometabolic measures (SBP, DBP, LVMI, HbA1c, non-HDL-C) with higher AHEI-2010 scores and lower cardiometabolic measures (SBP, DBP, LVMI, BMIz, z-WC, $\mathrm{HbA1C}, \mathrm{HDL}-\mathrm{C}$ ) with more anti-inflammatory diet scores.

There were no significant differences in baseline characteristics between the sub-sample of participants invited to follow-up ( $N=$ 74) who attended follow-up visits $(n=33)$ compared with those who did not attend follow-up visits $(n=41)$ (Supplemental Table 1). However, compared with those who did not attend follow-up visits, participants who did tend to be younger, male, and have a higher neighborhood household income. Changes in cardiometabolic characteristics from baseline to follow-up among those who attended follow-up visits $(n=33)$ are presented in Supplemental Table 2. There were no significant differences in average clinical or laboratory measures from baseline to follow-up, nor were there significant changes in presence of cardiometabolic conditions. However, the percentage of participants prescribed blood pressure medications increased from $46 \%$ at baseline to $64 \%$ at follow-up.

Among the participants who attended follow-up visits $(n=33)$, all participants received nutrition education at the baseline visit that comprises increasing fruits/vegetables $(n=30 ; 91 \%)$, limiting sodium intake $(n=30 ; 91 \%)$, promoting sugar-free beverages $(n=$ $22 ; 67 \%)$, portion control $(n=17 ; 52 \%)$, healthy alternative snacks $(n=16 ; 48 \%)$, and promoting three meals per day $(n=12 ; 36 \%)$. Over follow-up, there were significant reductions in energy intake $(m=-302 \mathrm{kcal} /$ day; $p$-value $=0.03$ ) that was mainly driven by changes reported among adolescents $9-13$ years $(m=-660 \mathrm{kcal} /$ day; $p$-value $=0.01$ ). There were no significant changes in reported intake of food groups/drinks, dietary fat, vitamins or minerals nor were there significant changes in AHEI-2010 ( $p$-value $=0.73$ ) or C-DIl scores ( $p$-value $=0.85$ ) across follow-up controlling for total energy intake.

There were differences in the reported reduction of total energy intake over follow-up by the type of dietary education received at baseline (Supplemental Fig. 1). Participants who received nutrition education on portion control reported the largest reduction in total energy intake $(-380 \mathrm{kcal} / \mathrm{d})$ followed by limiting sodium 
Table 3. Diet quality of participants included in the final sample $(n=90)$ compared with recommendations.

\begin{tabular}{|c|c|c|}
\hline & Final sample & Recommendations $^{a}$ \\
\hline Sample size & $N=90$ & \\
\hline \multicolumn{3}{|c|}{ Diet quality scores, mean $\pm S D$} \\
\hline AHEI-2010 score ${ }^{b}$ & $55.04 \pm 9.86$ & 0 to 110 (higher $=$ better) \\
\hline C-DII score ${ }^{c}$ & $-0.12 \pm 0.86$ & $\begin{array}{l}-5 \text { to } 5 \text { (lower }=\text { anti- } \\
\text { inflammatory) }\end{array}$ \\
\hline \multicolumn{3}{|l|}{ Total intake, mean $\pm S D$} \\
\hline $\begin{array}{l}\text { Energy, kcal (total } \\
\text { sample) }\end{array}$ & $1792 \pm 734$ & - \\
\hline $4-8$ years $(n=13)$ & $1539 \pm 379$ & - \\
\hline $9-13$ years $(n=33)$ & $1740 \pm 690$ & - \\
\hline $14-18$ years $(n=39)$ & $1770 \pm 440$ & - \\
\hline $19-21$ years $(n=5)$ & $1923 \pm 868$ & - \\
\hline Dietary fiber, $\mathrm{g} / \mathrm{d}$ & $13.3 \pm 7.5$ & $22-31$ g/d (goal) ${ }^{d}$ \\
\hline Fat, $\%$ & $33.3 \pm 7.5$ & $20-35 \%$ (goal) $^{d}$ \\
\hline Protein, \% & $17.3 \pm 5.8$ & $10-35 \%$ (goal) $^{d}$ \\
\hline $\mathrm{CHO} \%$ & $49.3 \pm 9.2$ & $45-65 \%$ (goal) $^{d}$ \\
\hline \multicolumn{3}{|c|}{ Food groups/drinks, median (IQR) } \\
\hline Fruit, servings/d & $0.00(0.00,1.00)$ & 4 servings/d (goal) \\
\hline Vegetable, servings/d & $1.63(0.63,2.49)$ & 5 servings/d (goal) \\
\hline Whole Grains, g/d & $4.7(0.0,31.9)$ & $75-90 \mathrm{~g} / \mathrm{d}\left(\right.$ goal $^{\mathrm{e}}$ \\
\hline $\begin{array}{l}\text { Nuts \& Legumes, } \\
\text { servings/d }\end{array}$ & $0.00(0.00,0.00)$ & 1 serving/d (goal) ${ }^{e}$ \\
\hline $\begin{array}{l}\text { Red/Processed Meat, } \\
\text { servings/d }\end{array}$ & $0.30(0.00,1.59)$ & 1.5 servings/d (limit) \\
\hline SSB, servings/d & $0.56(0.00,1.50)$ & 1 serving/d (limit) ${ }^{e}$ \\
\hline Alcohol, drinks/d & $0.00(0.00,0.00)$ & 0 servings $/ \mathrm{d}$ (limit) ${ }^{\mathrm{e}}$ \\
\hline \multicolumn{3}{|l|}{ Dietary fat, median (IQR) } \\
\hline Cholesterol, mg/d & $210(118,304)$ & $<300 \mathrm{mg} / \mathrm{d}$ (limit) ${ }^{\mathrm{d}}$ \\
\hline Saturated fat, \% kcal & $10.7(8.5,12.2)$ & $10 \%$ kcal (limit) ${ }^{d}$ \\
\hline MUFA, \% kcal & $11.1(9.3,13.2)$ & $15 \%$ kcal (goal) ${ }^{d}$ \\
\hline PUFA, \% kcal & $8.2(5.8,10.7)$ & $10 \%$ kcal (goal) $^{\mathrm{e}}$ \\
\hline Trans fat, \% kcal & $0.8(0.5,1.2)$ & $1 \%$ kcal (limit) $)^{d}$ \\
\hline Omega-3 FA, mg/d & $1650(1040,2344)$ & $250 \mathrm{mg} / \mathrm{d}$ (goal) $^{\mathrm{d}}$ \\
\hline \multicolumn{3}{|l|}{ Vitamins, median (IQR) } \\
\hline Vitamin A (RE/d) & $516(272,944)$ & $400-900 \mathrm{RE} / \mathrm{d}$ (goal) $^{\mathrm{f}}$ \\
\hline Beta-carotene, $\mathrm{mcg} / \mathrm{d}$ & $534(173,1625)$ & $600-1500 \mathrm{mcg} / \mathrm{d}(\mathrm{goal})^{f}$ \\
\hline Vitamin $D, m c g / d$ & $3.8(1.8,7.7)$ & $15 \mathrm{mcg} / \mathrm{d}$ (goal) ${ }^{\mathrm{f}}$ \\
\hline Vitamin E, AT EQ/d & $6.6(4.3,9.4)$ & 7-11 AT EQ/d (goal) ${ }^{f}$ \\
\hline Vitamin C, mg/d & $45.0(24.2,98.5)$ & $45-75 \mathrm{mg} / \mathrm{d}\left(\right.$ goal $^{\mathrm{f}}$ \\
\hline Vitamin $B_{6}, \mathrm{mg} / \mathrm{d}$ & $1.6(1.1,2.3)$ & $0.6-1.3 \mathrm{mg} / \mathrm{d}(\mathrm{goal})^{\mathrm{f}}$ \\
\hline Vitamin $B_{12}, \mathrm{mg} / \mathrm{d}$ & $3.3(1.9,5.2)$ & $1.2-2.4 \mathrm{mg} / \mathrm{d}$ (limit) ${ }^{f}$ \\
\hline \multicolumn{3}{|l|}{ Minerals, median (IQR) } \\
\hline Thiamin, mg/d & $1.6(1.0,2.2)$ & $0.6-1.2 \mathrm{mg} / \mathrm{d}(\mathrm{goal})^{\mathrm{f}}$ \\
\hline Riboflavin, mg/d & $1.7(1.1,2.4)$ & $0.6-1.3 \mathrm{mg} / \mathrm{d}(\mathrm{goal})^{\mathrm{f}}$ \\
\hline Niacin, mg/d & $22.0(17.1,29.8)$ & $8-16 \mathrm{mg} / \mathrm{d}(\text { goal })^{\mathrm{f}}$ \\
\hline Total folate, $\mathrm{mcg} / \mathrm{d}$ & $288(222,535)$ & $200-400 \mathrm{mcg} / \mathrm{d}(\text { goal) })^{\mathrm{f}}$ \\
\hline Iron, mg/d & $11.2(8.2,17.2)$ & $8-15 \mathrm{mg} / \mathrm{d}\left(\right.$ (limit) ${ }^{f}$ \\
\hline Sodium, mg/d & $3191(2252,3718)$ & $1500-2300 \mathrm{mg} / \mathrm{d}$ (limit) $^{f}$ \\
\hline Potassium, mg/d & $1828(1402,2424)$ & $2300-3000 \mathrm{mg} / \mathrm{d}(\mathrm{goal})^{\mathrm{f}}$ \\
\hline Magnesium, mg/d & $205(155,272)$ & $240-410 \mathrm{mg} / \mathrm{d}(\mathrm{goal})^{\mathrm{f}}$ \\
\hline Zinc, mg/d & $8.6(6.3,12.5)$ & $8-11 \mathrm{mg} / \mathrm{d}(\text { goal })^{\mathrm{f}}$ \\
\hline Selenium, mcg/d & $107(78,137)$ & $30-55 \mathrm{mg} / \mathrm{d}\left(\right.$ goal) ${ }^{\mathrm{f}}$ \\
\hline
\end{tabular}

AHEI-2010 alternative healthy eating index, C-DII children's dietary inflammatory index, $C H O$ carbohydrate, SSB sugar-sweetened beverages, MUFA mono-unsaturated fatty acid, PUFA polyunsaturated fatty acid, FA fatty acid, $R E$ retinol equivalents, $A T E Q$ alpha-tocopherol equivalents. Bold values indicate that intake was below or above recommended range.
aSample intakes (average or median) that do not meet recommended goals or limits are bolded.

${ }^{\mathrm{b}} \mathrm{AHEl}$-score ranges from 0 to 110 (higher $=$ better diet quality). Score increases with a higher intake of Fruit, Vegetables, Whole Grains, Nuts \& Legumes, PUFA, and Omega-3 fatty acid. Score decreases with higher intake of red/processed meat, SSB, trans fat, and sodium. Alcohol is scored between 0 (moderate alcohol consumption) - 2.5 (non-drinkers). ${ }^{c} \mathrm{C}$-DIl score ranges from -5 to 5 (lower $=$ better diet quality). Score increases (pro-inflammatory) with higher consumption of energy, fat, protein, carbohydrate, cholesterol, saturated fat, Vitamin $B_{12}$, and iron. Scores decreases (anti-inflammatory) with higher consumption of alcohol, fiber, MUFA, PUFA, Vitamin A, beta-carotene, Vitamin D, Vitamin $E$, Vitamin $C$, Vitamin $B_{6}$, thiamin, riboflavin, niacin, folate, magnesium, zinc, and selenium.

${ }^{\mathrm{d}}$ Recommendations based on the Dietary Guidelines for Americans (DGA). ${ }^{34}$ Range for fiber-based account for differences by age/sex. Percent of calories from macronutrients compared to the acceptable micronutrient distribution ranges (AMDR).

${ }^{\mathrm{e}}$ Recommendations based on the daily goals and thresholds proposed by Chiuve et al. ${ }^{14}$

${ }^{f}$ Recommendations based on the Dietary Reference Intakes (DRI) with ranges account for differences by age/sex. ${ }^{38-41}$

intake $(-374 \mathrm{kcal} / \mathrm{d})$, healthy alternative snacks $(-267 \mathrm{kcal} / \mathrm{d})$, sugar-free beverages $(-236 \mathrm{kcal} / \mathrm{d})$, increasing fruits/vegetables $(-203 \mathrm{kcal} / \mathrm{d})$, and promotion of 3 meals per day $(-154 \mathrm{kcal} / \mathrm{d})$.

\section{DISCUSSION}

Participants enrolled in the ReNEW clinic cohort study are youth with substantial obesity and multiple comorbid cardiovascular disease risk factors placing them at high risk for developing CVD in their lifetime. Average AHEI-2010 score was 55.04, which suggests $50 \%$ adherence to recommendations to achieve an optimal diet quality (out of a total of 110). ${ }^{14}$ The average C-DIl score of participants was -0.10 , which is roughly equivalent to $51 \%$ adherence to nutrient intake goals for an anti-inflammatory diet (out of a total range of 10). ${ }^{15}$ While not reaching statistical significance, children with greater diet quality as determined by AHEl had improved cardiometabolic point estimates at baseline than children with lower diet quality. Further, children with lower inflammatory diet scores had more favorable cardiovascular measures compared to those with higher inflammatory measures at baseline. While these AHEI-2010 and C-DIl scores did not change significantly over time, caloric intake did decrease with intensive dietary counseling to promote optimal diet quality, which achieved one of the clinical goals.

Diet quality scores in this high-risk sample were similar to estimates of diet quality in other youth populations. The average HEI scores of children 4-19 years participating in the Supplemental Nutrition Assistance Program (SNAP) was 45.6 (SD \pm 0.6 ), roughly translating to $46 \%$ adherence to the dietary guidelines for Americans. ${ }^{41}$ The average DIl scores of children 9-17 years from Spain was $0.24(S D \pm 1.67)$, indicating adherence to $49 \%$ of recommendations for an anti-inflammatory diet (out of a total range of 20). ${ }^{42}$ Thresholds were established for realistic energy reporting, and interpretation of average intake should take into account the age range of participants (4-21 years). Average calorie intake was presented over the total sample and stratified by age demonstrating increasing intake with higher age categories at baseline. Percent of energy was distributed within the ranges for acceptable macronutrient distribution for fat, protein, and carbohydrate. $^{34}$

Considering AHEI-2010 components, median intake was lower than recommendations for fruits, vegetables, whole grains, nuts/ legumes, and PUFA. ${ }^{14,34}$ Median intake was within daily limits set for red/processed meat, SSB, and alcohol; however median sodium intake $(3191 \mathrm{mg}$ ) was well above the daily limit based 
Table 4. Association between average diet quality score and blood pressure/LVMI measures.

\begin{tabular}{|c|c|c|c|c|c|}
\hline & \multicolumn{5}{|l|}{ Outcomes $^{a, b}$} \\
\hline & SBP index ${ }^{c}$ & DBP index ${ }^{c}$ & $S B P \geq 13$ years $(\mathrm{mmHg})$ & DBP $\geq 13$ years $(\mathrm{mmHg})$ & LVMI $\left(g / m^{2.7}\right)^{d}$ \\
\hline Sample size & $N=90$ & $N=90$ & $N=50$ & $N=50$ & $N=82$ \\
\hline $\begin{array}{l}\text { Low diet quality } \\
\text { High diet quality }\end{array}$ & $\begin{array}{l}\text { Reference } \\
-0.02(-0.07,0.02)\end{array}$ & $\begin{array}{l}\text { Reference } \\
0.01(-0.05,0.06)\end{array}$ & $\begin{array}{l}\text { Reference } \\
-3.11(-11.35,5.12)\end{array}$ & $\begin{array}{l}\text { Reference } \\
-1.33(-8.24,5.59)\end{array}$ & $\begin{array}{l}\text { Reference } \\
-0.88(-6.85,5.09)\end{array}$ \\
\hline \multicolumn{6}{|l|}{ C-DII score ${ }^{f}$} \\
\hline
\end{tabular}

SBP systolic blood pressure, DBP diastolic blood pressure, LVMI left ventricular mass index, $A H E I-2010$ alternative healthy eating index $2010, C-D I l$ children's dietary inflammatory index.

${ }^{a}$ Each column represents a separate regression model to estimate the effect of quantile diet quality score on continuous outcomes (SBP index, DBP index, SBP, DBP, LVMI). Beta-coefficients and confidence intervals (C.I.) presented.

${ }^{b}$ All models controlled for age (years), sex (boys, girls), total energy intake (scaled per 1000 kcal), average neighborhood household income (annual in US dollars), and blood pressure medication (yes, no).

${ }^{\mathrm{c}}$ Blood pressure index was calculated as raw, mean blood pressure divided by the age, sex, and height specific blood pressure at the $95^{\text {th }}$ percentile (\%tile) for all participants (95\%tile measures at 17 years of age were used for those $>17$ years).

'Left ventricular mass index (LVMI) determined in patients who received an echocardiogram $(n=82)$.

eAverage AHEI-2010 score broken into groups based on the median intake of the sample. Range of scores: low diet quality (below median: 34.56-54.65), high diet quality (above median: 55.19-78.80) (higher score/quantile = higher diet quality).

${ }^{f}$ Average C-DIl score broken into groups based on the median intake of the sample. Range of scores: pro-inflammatory diet (above median: 0.05-1.22), antiinflammatory diet (below median: -2.14 to -0.04 ) (lower score/quantile = more anti-inflammatory diet).

on the Dietary Guidelines for Americans (DGA; $2300 \mathrm{mg} /$ day limit). ${ }^{14,34}$ Comparing intake of dietary components considered pro-inflammatory with the DGA or dietary reference intake (DRI) ranges based on age and sex, median intake of dietary components considered pro-inflammatory was high for saturated fat, and above the DRI for Vitamin $B_{12}{ }^{34,35}$ Intake of dietary components considered anti-inflammatory was low for dietary fiber, MUFA, PUFA, beta-carotene, Vitamin D, Vitamin E, and magnesium. ${ }^{35-37}$ Intake of all remaining dietary components did not cross the upper limit of recommended thresholds for proinflammatory components and met the DRI for anti-inflammatory components. Given the low reported intake of fruit/vegetables in the sample, unsurprisingly, median potassium intake $(1828 \mathrm{mg})$ compared with the DGA (2300-3000 mg/day) was low. ${ }^{34}$

Over the course of follow-up, participants in the sub-group reported a decrease in energy intake $(m=-302 \mathrm{kcal} /$ day) within 12-months follow-up from a clinical program centered on educational approaches to promote lifestyle change. Type of education received impacted reported reductions in total energy intake, which was highest when participants received education on portion control at baseline $(-380 \mathrm{kcal} / \mathrm{d})$. Although there were no significant reductions in anthropometric or laboratory risk factors for CVD over the course of follow-up, findings should be considered in the context of this high-risk study sample were even maintaining anthropometric measures between clinic visits is a positive outcome. Not all participants had a documented medical diagnosis of overweight/obesity $(n=79 / 90)$ even though all of them presented to the clinic overweight or obese. Therefore, it is unclear what level of education participants had received prior to enrollment. Although all participants who attended follow-up visits received nutrition education at the baseline visit, the majority only had 1 follow-up within 7 months of baseline. In addition, education alone may not be enough to change dietary behaviors ${ }^{43}$ and do not address barriers of accessibility and affordability to healthy foods. ${ }^{44} \mathrm{~A}$ systematic review evaluating interdisciplinary interventions lasting between 3 months and 3 years on adolescent weight loss indicated that few programs impacted weight and often initial weight loss observed in participants was not sustainable. ${ }^{45}$
Participants with higher quantile AHEI-2010 scores and more anti-inflammatory diets trended towards lower SBP, DBP, LVMI, $\mathrm{HbA} 1 \mathrm{C}$, and non-HDL-C. Participants with anti-inflammatory diets also trended toward lower BMI and WC $z$-scores that may have reached significance with a larger sample size. The C-DII is made up of individual nutrients and does not account for the synergistic interactions of bioactive components found in whole foods. ${ }^{46}$ Reported intake was within thresholds/daily limits for the majority of foods/nutrients, but was lower than recommended for fruits/ vegetables, fiber, nuts/legumes, MUFA, PUFA, fat-soluble vitamins, potassium and magnesium and elevated for saturated fat, Vitamin $B_{12}$ and sodium. Nutrition counseling with continued emphasis on the promotion of fruits/vegetables while limiting sodium intake may benefit from the addition of healthy dietary fat (promoting nuts/legumes, MUFA, PUFA; limiting saturated fat) as a more comprehensive approach to improve clinical outcomes.

\section{LIMITATIONS}

Participants referred into the ReNEW clinic cohort study are referred based on the presence of overweight/obesity and elevated BP, limiting the generalizability of the cross-sectional findings from baseline. Furthermore, there were a limited number of participants ( $n=33 / 74 ; 46 \%$ ) with follow-up visits within 12 months of their baseline visit. In addition to these analyses being underpowered, the frequency and number of return visits among ReNEW adolescents varied by whether or not there was presence of elevated blood pressure at baseline, which may have introduced selection bias in the analysis of change from baseline to follow-up visit. ${ }^{47}$ Another limitation is that dietary data was collected via different collection techniques (24-h recall, 3-day diet record), however, both instruments relied on free form reporting confirmed by the research dietitian. The majority of dietary data (70\%) was collected by $24-\mathrm{h}$ recall, which tends to underestimate total energy intake and does not capture usual intake. ${ }^{48}$ However, children were interviewed by a highly trained research dietitian to assist with the accuracy of the reporting. These caveats should be taken into account when interpreting the non-significant associations between diet and cardiometabolic health. 
Table 5. Association between average diet quality score and anthropometric/cardiometabolic measures.

\begin{tabular}{|c|c|c|c|c|}
\hline & \multicolumn{4}{|l|}{ Outcomes ${ }^{a, b}$} \\
\hline & BMIz ( $\leq 18$ years) & $z-W C$ & HbA1c (\%) & Non-HDL C (mg/dL) \\
\hline Sample size & $N=80$ & $N=80$ & $N=72$ & $N=73$ \\
\hline $\begin{array}{l}\text { C-DII score } \\
\text { Pro-inflammatory diet } \\
\text { Anti-inflammatory diet }\end{array}$ & $\begin{array}{l}\text { Reference } \\
-0.18(-0.39,0.02)\end{array}$ & $\begin{array}{l}\text { Reference } \\
-0.21(-0.57,0.15)\end{array}$ & $\begin{array}{l}\text { Reference } \\
-0.11(-0.99,0.79)\end{array}$ & $\begin{array}{l}\text { Reference } \\
-3.99(-23.04,15.06)\end{array}$ \\
\hline
\end{tabular}

$B M I z$ body mass index $z$-score, $z$-WC waist circumference $z$-score, HbA1c hemoglobin A1c, non-HDL C non-high density lipoprotein cholesterol, AHEl-2010 alternative healthy eating index 2010, C-DIl children's dietary inflammatory index.

${ }^{a}$ Each column represents a separate regression model to estimate the effect of quantile diet quality score on continuous outcomes (BMIz, z-WC, HbA1C, nonHDL C). Beta-coefficients and confidence intervals (C.I.) presented.

${ }^{b}$ All models controlled for age (years), sex (boys, girls), total energy intake (scaled per $1000 \mathrm{kcal}$ ), and average neighborhood household income (annual in US dollars).

${ }^{c}$ Models additionally controlled for insulin/oral agent medication (yes, no).

${ }^{\mathrm{d}}$ Average AHEI-2010 score broken into groups based on the median intake of the sample. Range of scores: low diet quality (below median: 34.56-54.65), high diet quality (above median: 55.19-8.80) (higher score/quantile = higher diet quality).

${ }^{\mathrm{e}}$ Average C-DIl score broken into groups based on the median intake of the sample. Range of scores: pro-inflammatory diet (above median: 0.05-1.22), antiinflammatory diet (below median: -2.14 to -0.04 ) (lower score/quantile $=$ more anti-inflammatory diet).

\section{CONCLUSIONS}

More favorable scores trended toward improved cardiometabolic measures in high-risk, majority Black adolescents. However, likely due to the small sample size, these associations did not reach statistical significance. As such, they should be explored in larger studies. While our nutrition education did not improve diet quality among these high-risk adolescents over up to a year of follow-up, outpatient dietary counseling did result in reduced total energy intake in obese, hypertensive children and adolescents.

\section{REFERENCES}

1. CDC. Heart Disease Facts. cdc.gov (Centers for Disease Control and Prevention, 2020). https://www.cdc.gov/heartdisease/facts.htm. Accessed 21 Feb, 2021.

2. Hales, C. M. Prevalence of obesity among adults and youth: United States, 20152016. NCHS Data Brief. 288, 1-8 (2017).

3. CDC. Rates of New Diagnosed Cases of Type 1 and Type 2 Diabetes Continue to Rise Among Children, Teens. https://www.cdc.gov/diabetes/research/reports/childrendiabetes-rates-rise.html. Accessed 21 Feb, 2021 (2020).

4. CDC. CDC Surveillance System: Percentage of Children and Adolescents Having Hypertension. https://nccd.cdc.gov/ckd/detail.aspx?Qnum=Q247\&Strat=Year\#refresh Position. Accessed 21 Feb, 2021.

5. Funtikova, A. N., Navarro, E., Bawaked, R. A., Fíto, M. \& Schröder, H. Impact of diet on cardiometabolic health in children and adolescents. Nutr. J. 14, 118 (2015).

6. Sethna, C. B. et al. Dietary inflammation and cardiometabolic health in adolescents. Pediatr. Obes. 16, e12706 (2021).

7. Bradlee, M. L., Singer, M. R., Qureshi, M. M. \& Moore, L. L. Food group intake and central obesity among children and adolescents in the Third National Health and Nutrition Examination Survey (NHANES III). Public Health Nutr. 13, 797-805 (2010).

8. Pan, Y. \& Pratt, C. A. Metabolic syndrome and its association with diet and physical activity in US adolescents. J. Am. Diet. Assoc. 108, 276-286 (2008).

9. Wrobleski, M. M. et al. Comparison of the HEl and HEl-2010 diet quality measures in association with chronic disease risk among low-income, African American urban youth in Baltimore, Maryland. J. Am. Coll. Nutr. 37, 201-208 (2018).

10. Suhett, L. G. et al. Dietary inflammatory potential, cardiometabolic risk and inflammation in children and adolescents: a systematic review. Crit. Rev. Food Sci. Nutr. 61, 407-416 (2021).

11. Johns Hopkins University. Reversing the Negative Cardiovascular Effects of Weight (ReNEW) Clinic Cohort Study. clinicaltrials.gov. https://clinicaltrials.gov/ct2/show/ NCT03816462. Accessed 21 Feb, 2021 (2021).

12. Schakel, S. F. Maintaining a nutrient database in a changing marketplace: keeping pace with changing food products-a research perspective. J. Food Compos. Anal. 14, 315-322 (2001).

13. Schakel, S. F., Buzzard, I. M. \& Gebhardt, S. E. Procedures for estimating nutrient values for food composition databases. J. Food Compos. Anal. 10, 102-114 (1997).
14. Chiuve, S. E. et al. Alternative dietary indices both strongly predict risk of chronic disease. J. Nutr. 142, 1009-1018 (2012).

15. Khan, S. et al. Design, development and construct validation of the children's dietary inflammatory index. Nutrients 10, 993 (2018).

16. Lapuente, M., Estruch, R., Shahbaz, M. \& Casas, R. Relation of fruits and vegetables with major cardiometabolic risk factors, markers of oxidation, and inflammation. Nutrients 11, E2381 (2019).

17. Estruch, R. et al. Primary prevention of cardiovascular disease with a mediterranean diet supplemented with extra-virgin olive oil or nuts. N. Engl. J. Med. 378, e34 (2018).

18. Zeraatkar, D. et al. Red and processed meat consumption and risk for all-cause mortality and cardiometabolic outcomes: a systematic review and meta-analysis of cohort studies. Ann. Intern. Med. 171, 703 (2019).

19. Malik, V. S. \& Hu, F. B. Sugar-sweetened beverages and cardiometabolic health: an update of the evidence. Nutrients 11, 1840 (2019)

20. Wang, Y. J., Yeh, T. L., Shih, M. C., Tu, Y. K. \& Chien, K. L. Dietary sodium intake and risk of cardiovascular disease: a systematic review and dose-response metaanalysis. Nutrients 12, 2934 (2020).

21. Navarro, P. et al. Predictors of the dietary inflammatory index in children and associations with childhood weight status: a longitudinal analysis in the lifeways cross-generation cohort study. Clin. Nutr. 39, 2169-2179 (2020).

22. Buendia, J. R., Bradlee, M. L., Daniels, S. R., Singer, M. R. \& Moore, L. L. Longitudinal effects of dietary sodium and potassium on blood pressure in adolescent girls. JAMA Pediatr. 169, 560-568 (2015).

23. Chmielewski, J. \& Carmody, J. B. Dietary sodium, dietary potassium, and systolic blood pressure in US adolescents. J. Clin. Hypertens. 19, 904-909 (2017).

24. Shivappa, N., Steck, S. E., Hurley, T. G., Hussey, J. R. \& Hébert, J. R. Designing and developing a literature-derived, population-based dietary inflammatory index. Public Health Nutr. 17, 1689-1696 (2014).

25. Kuczmarski, R. J. et al. 2000 CDC growth charts for the United States: methods and development. Vital Health Stat. 246, 1-190 (2002).

26. CDC. Assessing Your Weight. Centers for Disease Control and Prevention. https:// www.cdc.gov/healthyweight/assessing/index.html. Accessed 22 Feb, 2021 (2020).

27. National Center for Health Statistics (U.S.) (ed). Waist Circumference Measurement Methodology Study: National Health and Nutrition Examination Survey, 2016 (U.S. Department of Health and Human Services, Centers for Disease Control and Prevention, National Center for Health Statistics, 2019).

28. Li, C., Ford, E. S., Mokdad, A. H. \& Cook, S. Recent trends in waist circumference and waist-height ratio among US children and adolescents. Pediatrics 118, e1390-e1398 (2006).

29. Flynn, J. T. et al. Clinical practice guideline for screening and management of high blood pressure in children and adolescents. Pediatrics 140, e20171904 (2017).

30. Khoury, P. R., Mitsnefes, M., Daniels, S. R. \& Kimball, T. R. Age-specific reference intervals for indexed left ventricular mass in children. J. Am. Soc. Echocardiogr. 22, 709-714 (2009).

31. American Diabetes Association. Diagnosis and classification of diabetes mellitus. Diabetes Care 36 Suppl 1, S67-S74 (2014). 
32. Stone, N. J. et al. 2013 ACC/AHA guideline on the treatment of blood cholesterol to reduce atherosclerotic cardiovascular risk in adults: a report of the American College Of Cardiology/American Heart Association Task Force on practice guidelines. Circulation 129, S1-S45 (2014).

33. Forrestal, S. G. Energy intake misreporting among children and adolescents: a literature review. Matern. Child Nutr. 7, 112-127 (2011).

34. U.S. Department of Agriculture and U.S. Department of Health and Human Services. Dietary Guidelines for Americans, 2020-2025 9th edn (USDA, 2020).

35. Institute of Medicine (US) Standing Committee on the Scientific Evaluation of Dietary Reference Intakes and its Panel on Folate, Other B Vitamins, and Choline. Dietary Reference Intakes for Thiamin, Riboflavin, Niacin, Vitamin B6, Folate, Vitamin B12, Pantothenic Acid, Biotin, and Choline (National Academies Press, 1998).

36. Institute of Medicine (US) Committee to Review Dietary Reference Intakes for Vitamin D and Calcium. in Dietary Reference Intakes for Calcium and Vitamin D (eds Ross, A. C., Taylor, C. L., Yaktine, A. L., Del Valle, H. B.) (National Academies Press, 2011).

37. Institute of Medicine (US) Panel on Micronutrients. Dietary Reference Intakes for Vitamin A, Vitamin K, Arsenic, Boron, Chromium, Copper, lodine, Iron, Manganese, Molybdenum, Nickel, Silicon, Vanadium, and Zinc (National Academies Press, 2001).

38. StataCorp. Stata Statistical Software: Release 14 (StataCorp LP, College Station, TX, 2015).

39. Archer, E., Hand, G. A. \& Blair, S. N. Validity of U.S. Nutritional Surveillance: National Health and Nutrition Examination Survey Caloric Energy Intake Data, 1971-2010. PLoS ONE 8, e76632 (2013).

40. Goldberg, G. R. et al. Critical evaluation of energy intake data using fundamental principles of energy physiology: 1 . Derivation of cut-off limits to identify underrecording. Eur. J. Clin. Nutr. 45, 569-581 (1991).

41. Leung, C. W., Tester, J. M., Rimm, E. B. \& Walter, C. W. SNAP participation and dietsensitive cardiometabolic risk factors in adolescents. Am. J. Prev. Med. 52, S127-S137 (2017).

42. Correa-Rodríguez, M. et al. Dietary inflammatory index and cardiovascular risk factors in Spanish children and adolescents. Res Nurs. Health 41, 448-458 (2018).

43. Brown, T. \& Summerbell, C. Systematic review of school-based interventions that focus on changing dietary intake and physical activity levels to prevent childhood obesity: an update to the obesity guidance produced by the National Institute for Health and Clinical Excellence. Obes. Rev. 10, 110-141 (2009).

44. Kim, H. S., Park, J., Ma, Y. \& Im, M. What are the barriers at home and school to healthy eating?: overweight/obese child and parent perspectives. J. Nurs. Res. 27, e48 (2019).

45. Zolotarjova, J., Velde, G. T. \& Vreugdenhil, A. C. E. Effects of multidisciplinary interventions on weight loss and health outcomes in children and adolescents with morbid obesity. Obes. Rev. 19, 931-946 (2018).

46. Liu, R. H. Dietary bioactive compounds and their health implications. J. Food Sci. 78, A18-A25 (2013).
47. Measurement Error and Bias Ch. 4. https://www.bmj.com/about-bmj/resourcesreaders/publications/epidemiology-uninitiated/4-measurement-error-and-bias. Accessed 22 Feb 2021 (2020)

48. Foster, E. \& Bradley, J. Methodological considerations and future insights for 24hour dietary recall assessment in children. Nutr. Res. 51, 1-11 (2018).

\section{AUTHOR CONTRIBUTIONS}

K.D.-S., T.M.B., and V.G.L. conceptualized the analyzes. K.D.-S. analyzed data and wrote the first draft of the manuscript. T.M.B. is the PI of the ReNEW Clinic Cohort Study, enrolls participants, and delivers medical care to individuals in the study. D.V. is the research dietitian for the ReNEW Clinic Cohort Study, educates patients on dietary choices, collects dietary data, inputs data into NDSR, and provided dietary data linked to clinic visits. V.G.L. was involved in the manuscript preparation and oversaw all aspects, including the analyses and writing. L.E.C, N.M, and S.R. gave feedback to the analyses, and contributed to interpreting the findings. All authors approved the final manuscript

\section{COMPETING INTERESTS}

The authors declare no competing interests.

\section{CONSENT STATEMENT}

The ReNEW Clinic Cohort Study (NCT03816462) is human subjects research that has been approved by the Johns Hopkins IRB (IRB00056175). Participants in the cohort study agree to have their clinical data abstracted from the electronic medical record (EMR) and entered into a longitudinal clinic registry. The study is discussed with participants in the presence of their parent or legal guardian and those who agree to participant sign consent ( $\geq 18$ years) or assent ( $<18$ years) as appropriate.

\section{ADDITIONAL INFORMATION}

Supplementary information The online version contains supplementary material available at https://doi.org/10.1038/s41390-021-01893-w.

Correspondence and requests for materials should be addressed to Vanessa GarciaLarsen.

Reprints and permission information is available at http://www.nature.com/ reprints

Publisher's note Springer Nature remains neutral with regard to jurisdictional claims in published maps and institutional affiliations. 